\title{
Group Composition and Social Structure of Red-Shanked Doucs (Pygathrix nemaeus) at Son Tra Nature Reserve, Vietnam
}

\author{
Lawrence R. Ulibarri Kylen N. Gartland \\ Department of Anthropology, University of Oregon, Eugene, OR, USA
}

\section{Keywords \\ Band composition · Socioecology · Colobines · Multilevel societies · Fission-fusion · Social cohesion}

\begin{abstract}
Multilevel societies, consisting of multiple one-male multifemale units, are relatively rare among primates, but are more widespread in the odd-nosed colobines than other taxa. Multilevel societies are found particularly in snubnosed monkeys (Rhinopithecus) and have been debated in studies of proboscis monkeys (Proboscis). While it has been suggested that douc langurs (Pygathrix) may also form multilevel societies, the limited data available make the details of their social organization unclear. We aimed to establish a more comprehensive picture of the social organization of red-shanked doucs (Pygathrix nemaeus) and to address the question of whether this species forms multilevel societies, specifically collections of multiple distinct one-male units hereafter termed "bands." We collected $259 \mathrm{~h}$ of behavioral data at Son Tra Nature Reserve in Vietnam from February 2010 to May 2011. The mean band size was approximately 18 individuals. Bands were comprised of approximately 2.7 units, and each unit contained approximately 6.5 individuals. Units had an average sex ratio of 1.0:1.6. We observed
\end{abstract}

fission and fusion behaviors which were not correlated with phenological or weather measures. Activity budget data showed that fission and fusion behaviors between units were positively correlated with activity. Both vocalizations and vigilance increased when units engaged in fission. Based on this evidence, P. nemaeus at Son Tra Nature Reserve appear to engage in daily fission-fusion activity which does not vary between seasons. Additionally, our data suggest that these primates may form multilevel societies made up of distinct units. However, future data including proximity pattern analyses are necessary for confirmation.

๑) 2021 S. Karger AG, Basel

\section{Introduction}

Social organization is the size, composition, and cohesion of a primate society [Kappeler, 2019; Kappeler and van Schaik, 2002]. Primates form a variety of social organizations, including independently foraging one-male multi-female units (OMUs) and multilevel societies [Grueter and van Schaik, 2010]. Multilevel societies consist of multiple units which can range from tight bands to much looser associations [Grueter and van Schaik, 2010; Yeager, 1998]. Within Asian colobines, species that display a large karger@karger.com www.karger.com/fpr (c) 2021 S. Karger AG, Basel
Correspondence to:

Lawrence R. Ulibarri, larryu@ uoregon.edu 
degree $(>40 \%)$ of range overlap and behaviors such as coordinated travel, occupation of adjacent sleeping trees, or cofeeding within the same or adjacent patches have at times been subsumed under the umbrella term of multilevel societies [Grueter and van Schaik, 2010]. There is still no consensus, however, on whether these characteristics are determinant of multilevel structure as subsequent studies have treated species with these characteristics as distinct from multilevel societies [Grueter et al., 2012, 2020]. However, multilevel societies may also exhibit complete range overlap and tight cohesion, although relations among units are generally neutral [Grueter and van Schaik, 2009]. In this context, a "unit" refers to a reproductive unit containing at least 1 adult male and 1 adult female while the term "band" refers to a social level comprised of multiple units [Grueter et al., 2020]. When defining multilevel societies, spatial proximity patterns are often a key delineating factor for establishing the existence of core units [Grueter et al., 2012, 2020]. The term "trooping" is used to describe the fusion of multiple bands [Qi et al., 2014]. Multilevel societies and fission-fusion dynamics are not mutually exclusive. Multilevel societies may be characterized by molecular fission-fusion, such as that observed in snub-nosed monkeys (Rhinopithecus). However, some multi-male multi-female social systems may also display fission-fusion dynamics (specifically termed atomistic fission-fusion such as that seen in chimpanzees, Pan troglodytes). One of the primary differences between these two forms of fission-fusion dynamics is the stability of subunit membership. Societies with atomistic fissionfusion dynamics often have stable community membership but instability in the size and composition of subunits whereas multilevel societies with molecular fission-fusion dynamics display relative inflexibility in both unit and band membership. Solitary individuals as well as all-male "bachelor" groups of primarily subadult or adult individuals have also been observed in species that form units or multilevel societies [Grueter et al., 2017].

Of particular interest within the theoretical study of multilevel societies are the ecological factors which may influence the degree of observed variation in group composition, structure, and fission and fusion behaviors. The ecological constraints model has frequently been proposed as a theoretical explanation for unit size and composition [Wrangham et al., 1993; Chapman et al., 1995; Gillespie and Chapman, 2001]. This model is centered on the theory that group size is limited by feeding competition within a group, and thus is governed by food availability and environmental factors which may influence variation in food availability.
The genera Rhinopithecus, Nasalis, Simias, and Pygathrix are a subset of the Asian colobines colloquially classified as the odd-nosed colobines. Odd-nosed colobines show intraspecific variation in social organization in response to differing environmental pressures [CluttonBrock and Harvey, 1977; Newton, 1988; Kirkpatrick et al., 1998]. The multilevel societies like those found in oddnosed colobine species and humans are relatively uncommon within the order Primates [Grueter and van Schaik, 2009]. It has been proposed that the unique feeding ecology of odd-nosed colobines has functioned as an ecological precondition for the emergence of multilevel societies [Grueter and van Schaik, 2010]. Odd-nosed colobines are adapted to rely more heavily on nonlimiting and ubiquitous resources and show an unusually low intensity of scramble competition which favors the evolution of multilevel societies [Grueter and van Schaik, 2010].

While published data on some species remain sparse, some socioecological trends have been established within the odd-nosed colobines. All snub-nosed monkeys and possibly Nasalis larvatus and $P$. cinerea, have been suggested or shown to form multilevel bands consisting of individual units [Schaller, 1985; Yeager, 1991; Bleisch et al., 1993; Kirkpatrick, 1995; Kirkpatrick et al., 1998; Zhang et al., 2006, 2008, 2012; Hoang, 2007; Cui et al., 2008; Qi et al., 2009; Ren et al., 2012; Ulibarri, 2013; Xiang et al., 2014; Grueter et al., 2017a, b ]. Studies of Rhinopithecus species suggest a diverse pattern of fission-fusion between units, including cohesive or seasonal patterns of banding [Grueter et al., 2017a; Kirkpatrick et al., 1998, 1999], and even sporadic fission of units [Dong, 2011]. Nasalis larvatus also forms units, but whether these units form multilevel societies is unclear. Some suggest there is a daily pattern of fission-fusion between units in multilevel societies [Matsuda et al., 2010; Yeager, 1991, 1992, 1995]. The simakobu monkey (Simias concolor, referred to historically as the pig-tailed snub-nosed monkey or langur) forms mixed-sex groups of adult male and adult female pairs, consisting typically of between 2 and 5 individuals [Tilson, 1977; Erb, 2012], but has not been described as forming multilevel societies [Tenaza, 1989; Tenaza and Fuentes, 1995].

Odd-nosed colobines, excluding $R$. roxellana, are among the least studied primates [Bennett and Davies, 1994; Kirkpatrick, 2011], although the last 1-2 decades have seen a significant increase in research focusing on these primates. Still, they remain relatively understudied in comparison to African colobines and great apes. For instance, few studies have been conducted on any wild Pygathrix populations [Lippold, 1977; Long, 2007; Duc et 
al., 2009; Phiapalath et al., 2011]. Until 2007, only one study had been published on the behavior of one of the three species of doucs (Pygathrix nemaeus) in the wild [Lippold, 1977]. There has been a notable increase in studies of wild Pygathrix since 2007, including long-term studies of black-shanked doucs (Pygathrix nigripes) and gray-shanked doucs (Pygathrix cinerea) [Hoang, 2007; Ha, 2009; Rawson, 2009] and field studies of red-shanked doucs [Phiapalath, 2009; Anh et al., 2010; Phiapalath et al., 2011]. Many studies tend to focus on conservation and distribution rather than socioecology, likely as a consequence of their conservation status, the dearth of habituated populations, and uniquely challenging observation conditions [Nhat, 1993b; Timmins and Duckworth, 1999; Long, 2007; Anh et al., 2010; Bett et al., 2012; Coudrat et al., 2012].

Red-shanked doucs can form a variety of social organizations including OMUs, multi-male units, all-male units, or solitary individuals [Lippold, 1977, 1995]. However, it has not been established whether these various units form a multilevel society. Solitary individuals can be both males and females, although it was unclear whether this was the result of dispersal by both sexes or related to other factors such as hunting and habitat disturbance [Lippold, 1977]. Pygathrix social units tend to have an approximate 1:2 ratio of adult males to adult females, regardless of whether the unit contains one or multiple males, as reported for most colobines [Kirkpatrick, 2011]. Group size estimates range from 3 to 45 individuals [Nhat, 1993a; Phiapalath, 2009; Ratajszczak et al., 1990], although whether these estimates referred to OMUs or bands is unclear. Unlike Rhinopithecus and Nasalis, no species of Pygathrix has been confirmed to form multilevel societies, and whether they engage in fission-fusion activities varies between reports. One study of redshanked doucs reported that larger groups regularly split into smaller units in the morning, then regrouped in the afternoon, but this was not explicitly termed multilevel or fission-fusion events [Anh et al., 2010]. In gray-shanked doucs, fluctuations in group sizes were reported with increased group sizes when young leaves were abundant, although it is not clear whether "group" referred to units or bands [Ha, 2009]. While fission-fusion of units and bands has been reported in black-shanked doucs, whether this constituted a multilevel society, fission-fusion dynamics, or random events was not concluded [Hoang, 2007].

Red-shanked doucs have been recorded on Son Tra since 1812 [Anh et al., 2010; Sterling et al., 2006; Thanh et al., 2007; Van Peenen et al., 1969]. Our primary aims

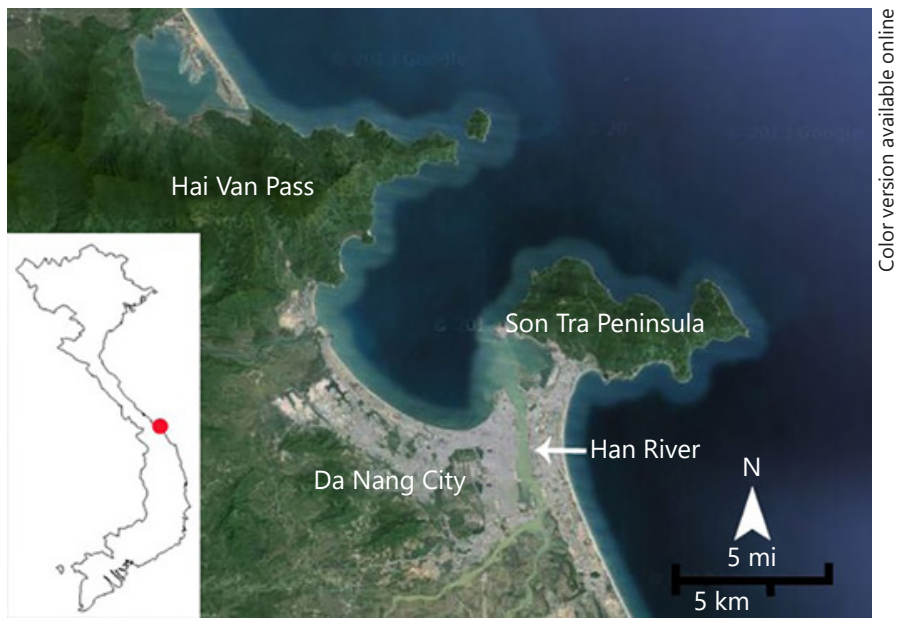

Fig. 1. Map of Son Tra.

are to assess the size and composition of units and bands and examine the factors influencing the social organization and band composition of red-shanked doucs. While it has been established that red-shanked doucs form a variety of types of social units which may engage in some form of fission-fusion activity, there is limited information concerning whether this constitutes a multilevel society or a multi-male multi-female society, or how seasonality or activity influence their social organization. These findings are important for establishing a socioecological foundation for $P$. nemaeus social structure and organization. Furthermore, this study provides a basis for comparing elements of social organization with those observed in other long-term Pygathrix field studies (e.g. see Hoang, 2007; Ha, 2009; Rawson, 2009], in addition to adding to the current understanding of potentially unifying socioecological trends amongst the odd-nosed colobines and, more broadly, the Asian colobines.

In light of the multilevel societies observed in most odd-nosed colobine species, we hypothesize that (1) redshanked doucs exhibit fission-fusion dynamics and (2) red-shanked doucs form multilevel societies. If the first hypothesis is supported, we predict that (a) fission-fusion behaviors will follow a daily pattern as suggested by Anh et al. [2010], and (b) we will observe increased fusion activities during young leaf abundance similar to that reported in gray-shanked doucs [Ha, 2009]. If the second hypothesis is supported, we predict that (a) the study population will demonstrate stable subunits with inflexible membership, and (b) subunits will demonstrate a predictable band-level association with inflexible membership. 


\section{Methods}

\section{Study Site}

We conducted this study at Son Tra Nature Reserve, on the Son Tra Peninsula in south-central Vietnam $\left(16^{\circ} 06^{\prime} \mathrm{N}\right.$ to $16^{\circ} 09^{\prime} \mathrm{N}$ and $108^{\circ} 13^{\prime}$ E to $108^{\circ} 21^{\prime}$ E) (Fig. 1) [Lippold, 1977; Tordoff et al., 2004].

Son Tra Peninsula measures approximately 4,552 ha in size, and at the time of this study the Nature Reserve measured 2,670 ha. Son Tra Nature Reserve has a high biodiversity value [Anh, 1997]. The Son Tra protected area has experienced increasing fragmentation as a result of roads and development [Lippold and Thanh, 2008]. Son Tra Peninsula is home to one of Vietnam's largest verified subpopulations of red-shanked doucs and at the beginning of data collection in 2010, it was the only known site where red-shanked doucs could be reliably observed in the wild due in part to the small size of the peninsula, the large population of doucs, and the high habitat fragmentation due to road construction. Preliminary surveys covered the entire peninsula. Following the selection of a primary research band, we focused observations on this band and their home range. We also selected and regularly observed two secondary bands.

\section{Subjects}

We classified individuals by sex and age based on coloration, body size, and development of sexual characteristics following previously established physical descriptions [Lippold, 1977; Ruempler, 1998], and prior research experience with these primates in Vietnam. Age classes included adult male ( $>4$ years), adult female (>3.5 years), subadult male (3-4 years), subadult female (2.5-3.5 years), juvenile ( $1.5-3$ years), and infant ( $0-1.5$ years). We identified and prioritized a primary research band based on successful habituation. Habituation techniques included the use of auditory signaling, waiting at key sites, and avoiding observations from upslope positions which disturbed the individuals [Williamson and Feistner, 2011]. Habituation of the primary research band permitted regular observations at close range (within $30 \mathrm{~m}$ ), range tracking, and individual recognition. Habituation allowed for fullday follows with animals largely ignoring the presence of observers following full habituation. Following habituation, we began by identifying a consistent location in which a band was sighted. We then quantified and described the number and make-up of units within the band according to age and sex classes. Individual identification was established using distinct facial, pelage, and vocal patterns. Following establishment of individual recognition, we were able to identify stable social clusters which became the basis for unit-level identification. From this point, units were readily verifiable by stable membership of visually recognizable individuals. We were then able to identify units by their demographic makeup, but still used individual identification of members for confirmation of which unit was being observed. We did not achieve the necessary level of habituation to allow for individual level recognition with the two secondary research bands. However, we still conducted observations with these secondary bands/units when we could not locate the primary research band.

\section{Data Collection}

We collected data from February 2010 to May 2011. Data collection typically occurred between sunrise (5:00 or 6:00 h) and sunset (17:00 or 18:00 h). Observers recorded GPS marks at the location of focal individuals. Unfortunately, we were unable to collect spatial proximity data for core unit analysis at this time. Dense canopy and unit dispersion often resulted in only 1 or 2 individuals being visible at a time. Generally, we selected the most visible individual as the focal subject. We alternated observations between adult males and females, similar to established methodology [Chapman, 1988; Garber, 1988]. We only collected data on subadult, juvenile, or infant individuals when no adult individual was visible.

Previous research at this site has reported that this population formed units of unknown membership demography and suggested that multilevel societies may be present [Anh et al., 2010]. Following established methodology, observers conducted 10-min focal animal follows with 1-min instantaneous scans [Altmann, 1974]. Recorded behavioral categories included inactivity, social behavior (including vocalizations), feeding, and locomotion. Focal individuals were chosen at random to prevent sampling bias. Observers used a Garmin GPSMap 60 CSx to record UTM locations of the focal animal with a waypoint accuracy of within a 5-m error. When other individuals were visible and within approximately 10 $\mathrm{m}$ of the focal individuals, observers also conducted instantaneous scan sampling to gain a more comprehensive picture of activity patterns and band composition. After we had become able to identify individual units from each other, we also began recording the approximate spatial distribution of units from each other. Units were readily verifiable after repeat encounters through recognition of individual members by distinct pelage and other bodily markings. Throughout the study period, units were further concretely verified by lack of shifts in membership composition. This permitted for an evaluation of unit fission-fusion at each data point. The primary field research period (February 2010 to May 2011) resulted in $1,619 \mathrm{~h}$ in the field with $259 \mathrm{~h}$ of contact with the red-shanked doucs. Observers spent 20 days in the field each month and approximately $12 \mathrm{~h}$ per day ensuring equal effort across months.

Although fission and fusion states are mutually exclusive and units within a band are either fissioned or fused, we were interested in studying the temporal distribution of fission and fusion events. As such, we only recorded data when units of a band were directly observed transitioning from one state to the other. We noted if units were already fused or fissioned on encounter but could not determine the timing of the event or duration without direct observation. In order not to overmeasure the frequency of these behaviors, we only recorded fission or fusion based on visual contact between OMUs. Following the guidelines for primate sensory ecology within secondary rain forest environments, we determined the visual barrier for this habitat to be approximately 30 $\mathrm{m}$ [Dominy et al., 2001]. As such, we only recorded a fusion event if previously separated units of a band approached one another to within about $30 \mathrm{~m}$, and a fission event if previously combined units of a band separated beyond $30 \mathrm{~m}$ of each other. We recorded the timing and duration of any fission or fusion state, when possible, with duration only interrupted by loss of the band or the end of daily observation (i.e., a fused band sleeping for the night). If we observed a fission, we continued observations with the closest available individual/unit in order to ensure the greatest continuity of data collection, to minimize the risk of losing contact with the focal individual/unit and to avoid unnecessary disturbance to the doucs.

We recorded observations of trooping, bachelor males, and allmale bands when encountered during observation of the primary and secondary research bands. 
Table 1. Band composition across research bands

\begin{tabular}{|c|c|c|c|c|c|c|c|c|}
\hline Unit & $\begin{array}{l}\text { Adult } \\
\text { males }\end{array}$ & $\begin{array}{l}\text { Adult fe- } \\
\text { males }\end{array}$ & $\begin{array}{l}\text { Subadult } \\
\text { females }\end{array}$ & $\begin{array}{l}\text { Subadult } \\
\text { males }\end{array}$ & Juveniles & Infants & Unidentified & Total \\
\hline \multicolumn{9}{|c|}{ Primary research band } \\
\hline Unit A & 2 & 3 & 1 & 1 & 1 & 4 & 0 & 12 \\
\hline Unit B & 1 & 2 & 2 & 0 & 0 & 1 & 0 & 6 \\
\hline Unit C & 1 & 1 & 0 & 0 & 1 & 0 & 0 & 3 \\
\hline Total & 4 & 6 & 3 & 1 & 2 & 5 & 0 & 21 \\
\hline \multicolumn{9}{|c|}{ Secondary research band } \\
\hline Unit D & 2 & 3 & 0 & 1 & 1 & 2 & 0 & 9 \\
\hline Unit E & 1 & 2 & 1 & 0 & 0 & 1 & 0 & 5 \\
\hline Total & 3 & 5 & 1 & 1 & 1 & 3 & 0 & 14 \\
\hline \multicolumn{9}{|c|}{ Tertiary research band } \\
\hline Unit F & 2 & 2 & 1 & 0 & 0 & 1 & 0 & 6 \\
\hline Unit G & 2 & 2 & 0 & 0 & 0 & 1 & 2 & 7 \\
\hline Unit H & 1 & 2 & 0 & 0 & 0 & 1 & 1 & 5 \\
\hline Total & 5 & 6 & 1 & 0 & 0 & 3 & 3 & 18 \\
\hline
\end{tabular}

We assessed phenology measurements using line transects within the protected area following previously established methods [Ganzhorn, 2003; Vogel and Dominy, 2011]. We performed three transects, two measuring $300 \mathrm{~m}$ by $8 \mathrm{~m}$ and one transect measuring $500 \mathrm{~m}$ by $8 \mathrm{~m}$, with locations determined using a random number generator using UTM coordinates. We catalogued all trees with a diameter at breast height of $\geq 10 \mathrm{~cm}$. This resulted in a total of 512 monitored trees. We monitored these transects every 2 weeks for the duration of the study to establish variation in forest productivity. In order to conduct analyses on a monthly scale, we took the arithmetic mean of the two measures per month. Transect records included measurements of phenophase including the percentage of leaf flush, leaf fall, and fruits and flowers for each tree [van Schaik et al., 1993]. Following established methodology, we defined $100 \%$ leaf flush as all terminal branches having young/mature leaves, $100 \%$ leaf fall as all terminal branches being bare. We also estimated fruiting and flowering from terminal branches [van Schaik et al., 1993]. We considered leaf buds to be young leaves. Terminal branches had to be flowering or fruiting in order to be considered in the overall estimate for the tree. We established crown width, height, and diameter at breast height for individual trees when we established the initial transect. We collected these phenology data to assess potential seasonal patterns in social organization.

We collected weather data from Son Tra Weather Station [Wunderground, 2013]. The Son Tra Weather Station was located approximately $1 \mathrm{~km}$ from the study site, and thus data were representative of weather conditions experienced by the study population.

\section{Statistical Analysis}

We chose statistics to make this study directly comparable to studies conducted of wild gray-shanked and black-shanked doucs [Hoang, 2007; Ha, 2009; Rawson, 2009; O’Brien, 2014]. To evaluate the relationship between unit sizes and phenology we used a two-tailed Pearson's correlation test $(\alpha=0.05)$. We restricted unit
Table 2. Fission-fusion events per month

\begin{tabular}{llll}
\hline Month & Fusion events & Fission events & Total \\
\hline February & 2 & 1 & 3 \\
March & 0 & 2 & 2 \\
April & 0 & 1 & 1 \\
May & 2 & 1 & 3 \\
June & 2 & 0 & 2 \\
July & 1 & 1 & 2 \\
August & 5 & 3 & 8 \\
September & 4 & 3 & 7 \\
October & 7 & 9 & 16 \\
November & 6 & 5 & 11 \\
December & 6 & 4 & 10 \\
January & 1 & 2 & 3 \\
February & 6 & 3 & 9 \\
March & 4 & 3 & 7 \\
April & 3 & 3 & 6 \\
May & 3 & 3 & 6 \\
\hline Total & 52 & 42 & 94 \\
\hline
\end{tabular}

size analyses to encounters in which we obtained a full count of the unit based on a minimum of $3-4 \mathrm{~h}$ of continuous observation (i.e., visual identification of all individuals that could be heard), and for units which contained at least one adult female and one adult male (i.e., we excluded all-male bands and single individuals from this analysis). We removed repeat counts of the same unit and only report band sizes for the three main research bands (one primary and two secondary) only.

We compared fission and fusion events with weather and phenology data on daily and seasonal scales using a Pearson's correla- 
Table 3. Correlation of fission-fusion events with temperature, precipitation, leaf flush, flowering, and fruiting

\begin{tabular}{llll}
\hline Variable & $R$ & $N$ & $\begin{array}{l}p \text { value } \\
(p=0.01 \\
\text { significant })\end{array}$ \\
\hline Temperature & -0.38 & 16 & 0.13 \\
Precipitation & 0.55 & 16 & 0.03 \\
Leaf flush & -0.59 & 13 & 0.03 \\
Flowering & -0.00 & 13 & 0.97 \\
Fruiting & 0.22 & 13 & 0.49 \\
\hline
\end{tabular}

tion test $(\alpha=0.05)$. We used a Bonferroni correction to address familywise error rate as a result of multiple comparisons, reducing the $\alpha$-value to 0.01 . As such, only $p$ values of 0.01 or less were considered significant. We addressed occurrences of trooping, bachelor males, and all-male bands descriptively given the small sample sizes. We report activity budgets focusing on inactive, locomotor, social, feeding and other behaviors descriptively following established methodology [Guo et al., 2007].

\section{Results}

\section{Unit Composition and Size}

Total unit composition was reliably measured in 17 nonrepeat unit encounters, yielding both sex and age class composition ratios (Tables 1-3). Units had a mean adult male-to-female sex ratio of 1.0:1.63 individuals and an adult-to-immature ratio of 1.1:1.0 individuals. Units furthermore contained a mean of $6.5 \pm 1.2$ individuals. Of units in the three main study bands, $41.1 \%$ contained more than 1 adult male. We observed multi-male units in all observation months. Within the three research bands, aside from one infant birth, one immigration, and one emigration event, unit size and structure remained consistent throughout this study. We observed two all-male "bachelor" groups, but we did not include them in unit or band size or composition analyses. Observers also recorded 13 encounters with solitary individuals all of whom were male.

\section{Band Composition and Size}

We were able to compile total composition and size data for the primary and tertiary research bands (Table 1). The tertiary research band had become fragmented due to road construction activities and was the least habituated band. One unit had been isolated in a 2-hectare section of fragmented forest as a result of road construction activities (unit F). The remaining two units of this band maintained proximity to the road and the forest fragment of the third isolated unit despite having access to the larger central forested block of Son Tra Reserve, suggesting these three units likely comprise a band which was separated by construction activities.

Bands of these three main research groups ranged in size between 14 and 21 individuals with a mean of $18 \pm$ 3.6 individuals per band, and $2.7 \pm 0.6$ units.

\section{Fission-Fusion}

Analyses of fission-fusion activity based on observed events yielded 94 separate recorded events of observed fissuring or fusing. $55.32 \%(N=52)$ of observations were fusion events while $44.68 \%(N=42)$ of observations were fission events. There was a peak in the rate of fission-fusion between units during the period of October to December which correlates with the mid-wet season (Table 2).

We also correlated the number of monthly fission-fusion events to weather and phenology measures with no significant results (Table 3). However, observations of fission-fusion events showed an increase in fission in the morning between 6:00 and 10:00 h, an increase in fusion in the vicinity of 10:00 to 11:00 $\mathrm{h}$, a second increase in fission in the early afternoon, and a second fusion in the later afternoon or early evening (Fig. 2a, b).

We found that daily fission and fusion events were significantly correlated with each other across both the wet and dry seasons $(r(14)=0.902, p<0.0001)$. There is no significant variation in daily events of fission $(\mathrm{U}=130.5$, $p=0.14, N_{\text {wet, dry }}=14,14$ ) between the wet and dry seasons. This indicates no significant variation in daily fission and fusion events between the seasons.

\section{Activity Budget}

We compared a daily activity budget of all adult individuals against hourly observations of fission and fusion events. Individuals spent $35.3 \%$ of their time in inactive behavior $(N=10,755), 28.6 \%$ in moving and locomotor behaviors $(N=8,717), 21.7 \%$ of time in social behaviors $(N=6,609), 13.7 \%$ of time in feeding behaviors $(N=$ $4,155)$, and $0.7 \%$ of time in other behaviors $(N=205)$. Social behaviors included vocalizations $(86.9 \%, N=5,746)$, displays (3.9\%, $N=260)$, grooming $(2.6 \%, N=169)$, playing $(6.4 \%, N=425)$, and copulation $(0.2 \%, N=12)$.

To compare activity budget data, we calculated the percentage of time spent fissioned. Since fission and fusion states are mutually exclusive, the remaining time was labeled as the percentage of time spent in a fusion state. Inactivity and movement were significantly correlated with fission-fusion activity (Fig. 3a, b). Inactiv- 

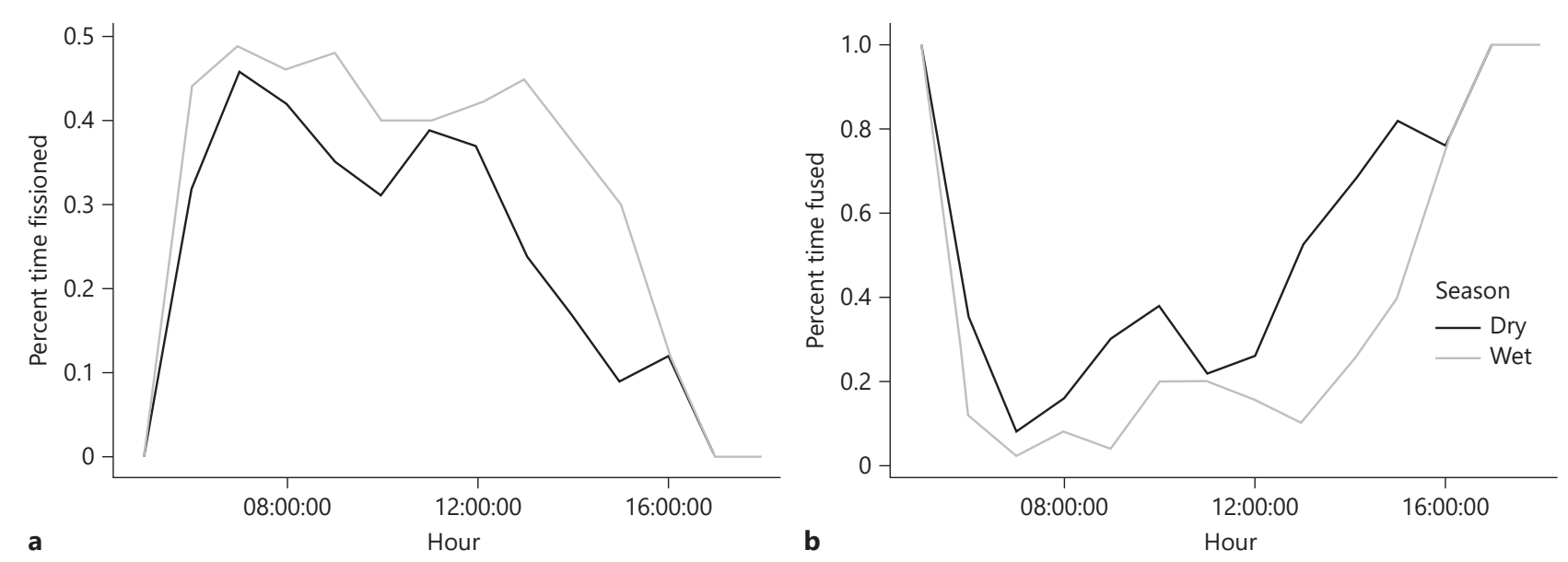

Fig. 2. Fission (a) and fusion (b) against time of day and season.

Fig. 3. a Fission against daily activity bud-

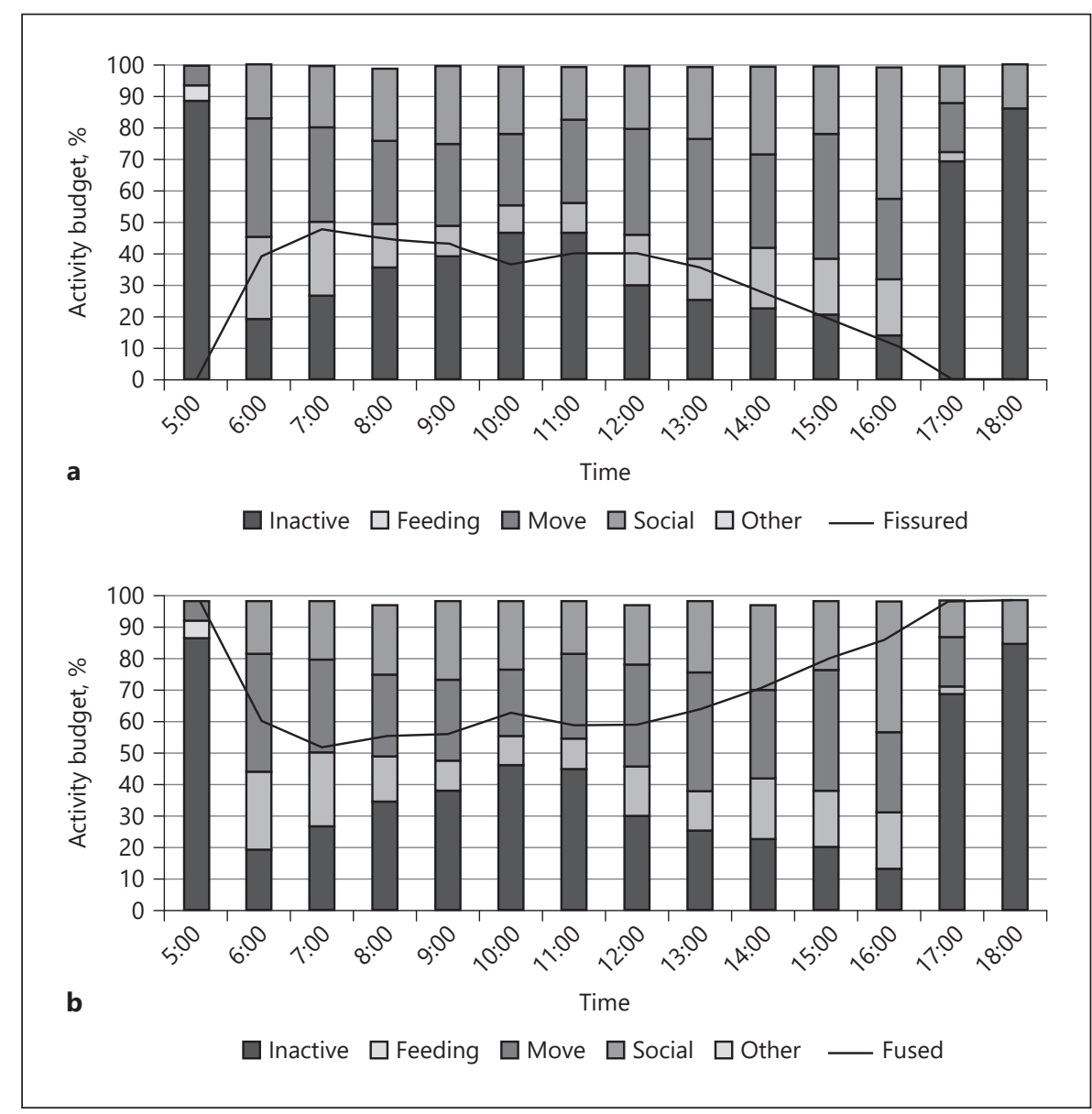


ity was significantly positively correlated with fusion events $(r(14)=-0.63, p=0.01)$ such that when units came together individuals were more likely to be inactive. Movement was significantly positively correlated with fission $(r(14)=0.69, p=0.01)$ such that individuals were more likely to be engaged in locomotor behaviors when units were independent of the larger band. Vocalizations, recorded specifically under social behaviors, were significantly positively correlated with fission-fusion activity such that vocalizations increased when units were fissured $(r(14)=0.81, p=0.0004)$ and decreased when units were fused $(r(14)=-0.81, p=$ $0.0004)$. Finally, there was a significant positive correlation between vigilance and fission-fusion activity such that vigilance increased when units were fissured $(r(14)=0.68, p=0.01)$ and decreased when units were fused $(r(14)=-0.68, p=0.01)$.

\section{Discussion}

The distribution range of the red-shanked doucs is restricted to many isolated and remnant subpopulations restricted to a patchwork of fragmented protected areas throughout Vietnam, Laos, and Cambodia [Lippold, 1977; Nhat, 1993a, b; Timmins and Duckworth, 1999; Nadler et al., 2003; Long, 2007; Rawson and Roos, 2008; Ha, 2009]. The population at Son Tra Nature Reserve contains one of the largest confirmed remaining subpopulations of $P$. nemaeus. As such, we propose that the social organization observed in this population may be largely representative of species-typical characteristics. However, we acknowledge that the restricted size of the forest block and continued forest fragmentation due to infrastructure developments may have influenced the socioecology of this population.

The observed unit and band sizes are comparable to other P. nemaeus studies [Lippold, 1995; Thanh et al., 2007; Ngoc Thanh et al., 2008; Anh et al., 2010]. However, previous studies have, for the most part, not distinguished between units, bands and trooping which makes direct comparisons somewhat imprecise. For example, one study reported that bands of red-shanked doucs could range in size between 4 and 26 individuals, which would appear to represent both units and bands within a single size estimate [Nhat, 1993b]. Previous studies specifically conducted at Son Tra have reported mean band sizes of 14.3 individuals [Lippold and Thanh, 2008] and 15.2 individuals [Anh et al., 2010], which is slightly smaller than the band size reported here.
Studies of other Pygathrix species have also been unclear in distinguishing between units and bands. Bands of gray-shanked doucs in Kon Ka Kinh National Park, Vietnam, were reported to have a mean of 14.8 individuals, although observations ranged from 2 to 88 individuals which suggests a combination of units, bands, and potentially trooping [Ha, 2009]. Some reports on black-shanked doucs include both unit and band levels in a single size estimate, impacting the accuracy of direct comparison across Pygathrix species [Rawson, 2009]. Hoang Minh Duc was the first Pygathrix researcher to distinguish between levels of social organization and reported band sizes at 22.8 \pm 9.0 individuals in Nui Chua National Park and $12.8 \pm 1.3$ individuals in Phuoc Binh National Park [Hoang, 2007]. Although these calculated band sizes may have included trooping, unlike the results presented here, the reported band sizes are still comparable. Despite a small area with an absence of predators and migration behavior, the unit composition and sizes observed in this population are generally comparable with other Pygathrix studies.

Within the primary research band we observed multiple types of units, including one pair-bonded unit, one OMU, and one multi-male unit. For the duration of this study (16 months), these units were stable. This does not necessarily mean that multi-male units and pair-bonded units are broadly frequent or stable across all bands of $P$. nemaeus or Pygathrix in general. This capacity for variation in unit composition within a single population has been previously illustrated in other species, particularly Guinea baboons [Patzelt et al., 2011, 2014]. It has been demonstrated that the OMU among colobines represents the ancestral state, and it has further been suggested that multilevel societies represent a derived state [Grueter and van Schaik, 2010]. It is possible that this variation in unit composition is the result of the absence of phylogenetic inertia, described as the outcome of the forces that originally influenced the ancestral formation of the OMU being reduced or removed while the newly evolving social structure(s) are actively molded under new or shifted forces [Chapman and Rothman, 2009]. Our data are suggestive of a multilevel social organization with a daily pattern of fission-fusion behaviors. Further research, particularly integrating proximity analyses for identification of core clusters, is necessary for confirmation of multilevel structure within this species. Furthermore, observations of fission-fusion events may have varied between bands due to the different levels of achieved habituation between the primary and the secondary/tertiary research bands. Stable units band together in stable bands. It also 
appears that this system permits for unit structural diversity, as we observed both multi-male and one-male units.

While fission-fusion refers to a continuum of degrees and characteristics highlighted by flexibility in societal membership, multilevel societies are characterized by relative inflexibility in both unit and band membership. Our study suggests that $P$. nemaeus may live in multilevel societies. Both unit and band levels are stable in membership, and the units of a band exhibit a daily pattern of fission-fusion which is significantly related to daily activity. The positive correlation between fissioning and vocalizations suggests that calls may be used to coordinate activities between the dispersed foraging units of a single multilevel society. However, future studies are necessary to confirm whether vocalizations serve to coordinate movement or serve other functions. One would expect increased vigilance in the presence of both multiple units and bachelors in nonmultilevel societies, as the outside units might present social threats or resource competition. The decrease in vigilance with fusion instead suggests that these units may have a degree of established familiarity. We also observed complete range overlap between units of the primary research band. This population of $P$. nemaeus conformed to a number of the characteristics of multilevel societies within Asian colobines, including large to complete range overlap, occupation of adjacent sleeping trees (or complete fusion during rest in our case), and neutral relations between individual units [Grueter and van Schaik, 2009]. However, further longitudinal data are necessary for confirmation of these preliminary observations.

While we observed daily patterns of fission-fusion between units, there was no fluidity in unit size across seasons. It is notable that this pattern of daily fission-fusion differs from genera such as Ateles and Pan which exhibit a fission-fusion society with flexible unit membership (sometimes referred to as individual-based fission-fusion) [Lehmann and Boesch, 2004; Wallace, 2008; Grueter and van Schaik, 2010].

The social structure exhibited by Pygathrix resembles fission-fusion, excepting the lack of flexibility in unit membership. This fission-fusion with inflexible membership has also been reported in Cacajao and Macaca fascicularis [van Schaik and van Noordwijk, 1989; Bowler and Bodmer, 2009]. All observed fusion events included units fusing overnight. It was thus unsurprising to find a significant correlation between fusion and sleeping or inactivity. We also observed significantly higher fission peaks in the morning and early afternoon, corresponding to peaks in movement as a possible function of foraging.

Group Composition in Red-Shanked

Doucs
While we observed increases in fission-fusion activity correlated with leaf flush, these results were insignificant. The pattern of fission and fusion among doucs may also regulate feeding competition [Kummer, 1968]. In some models, if resources were not overly scarce resulting in increased competition, or overly abundant resulting in decreased competition, fission and fusion could manifest naturally, leading to bond formations and complex social networks such as those within multilevel societies [Ramos-Fernandez et al., 2006]. We believe the daily pattern may allow for units both to avoid feeding competition and increase predation defense. A more specified testing of feeding competition and ecological constraints is necessary for future investigation.

Units and bands are stable and associate daily. We suggest that more studies need to include analysis at this daily scale. In our study, we observed a daily pattern of unit or band cohesion as demonstrated in activity budget and fission-fusion observations. Furthermore, we considered a number of possible environmental and ecological factors which may have been influencing unit and band size. The ecological constraints model suggests that feeding competition limits band size, which would therefore suggest that food availability is a primary influencing factor on band or unit size [Wrangham et al., 1993; Gillespie and Chapman, 2001]. Our data do not provide support for this as we observed no seasonality in fission-fusion activity among the doucs of Son Tra (i.e., bands fissure and fuse along a daily pattern, not a seasonal pattern). In the future, we suggest an investigation of this behavioral patterning from the theoretical perspective of the ecological constraints model.

Finally, we would like to acknowledge that we were not able to collect and analyze data pertaining to spatial proximity patterns at this time. Spatial proximity patterns are often a significant deciding factor in identifying or confirming the existence of distinct core units which are central to defining multilevel societies [Grueter et al., 2012, 2020]. Our results, while preliminary, support the existence of multilevel societies characterized by molecular fission-fusion within this population of red-shanked doucs. However, more extensive spatial proximity analyses are necessary to further explore these observations.

\section{Acknowledgements}

The study was possible thanks to the collaborative efforts of the Frankfurt Zoological Society, the Department of Science and Technology, the Department of Agriculture and Rural Development of Da Nang, the Da Nang Forest Protection Department, the Son Tra 
Ecotourism Management Board, the Dinh Thi Phuong Anh Da Nang University Committee Chair, the Department of Biology at Da Nang University, botanist Tran Ngoc Toan for plant identification, the Institute of Tropical Biology, Nong Lam University, and Bui Huy Hoang and Nguyen Hong Chung for their help in field research. We would also like to acknowledge the contributions of Dr. Joanna M. Setchell, Editor-in-Chief of the International Journal of Primatology, and our two anonymous reviewers.

\section{Statement of Ethics}

Our study was observational and noninvasive. All procedures performed in this study were in accordance with the legal requirements of Vietnam.

\section{Disclosure Statement}

The authors have no conflicts of interest to declare.

\section{Funding Sources}

This study was funded by the Margot Marsh Biodiversity Foundation, the Primate Society of Great Britain, the Endangered Primate Conservation Fund, and Frankfurt Zoological Society.

\section{References}

Altmann J (1974). Observational study of behavior: sampling methods. Behaviour 49: $227-$ 267.

Anh DTP (1997). Studies on the Fauna, Flora, and Impact Factors in Son Tra Nature Reserve with Recommendations of Rational Conservation Solutions. Da Nang, Da Nang University.

Anh DTP, Chung NDH, Hang HTN (2010). Status and distribution of red-shanked douc langurs (Pygathrix nemaeus) and threats to their population at Son Tra Nature Reserve, Danag City. In Conservation of Primates in Indochina (Nadler T, Rawson BM, Thinh VN, eds.), pp 71-78. Frankfurt, Frankfurt Zoological Society and Conservation International.

Bennett EL, Davies AG (1994). The ecology of Asian colobines. In Colobine Monkeys: Their Ecology, Behavior and Evolution (Davies G, Oates J, eds.), pp 129-172. Cambridge, Cambridge University Press.

Bett NN, Blair ME, Sterling EJ (2012). Ecological niche conservatism in doucs (genus Pygathrix). International Journal of Primatology 33: 972-988.

Bleisch W, Cheng AS, Ren XD, Xie JH (1993). Preliminary results from a field study of wild Guizhou snub-nosed monkeys (Rhinopithecus brelichi). Folia Primatologica 60: 72-82.

Bowler M, Bodmer R (2009). Social behavior in fission-fusion groups of red uakari monkeys (Cacajao calvus ucayalii). American Journal of Primatology 71: 976-987.

Chapman C (1988). Patterns of foraging and range use by three species of neotropical primates. Primates 29: 177-194.

Chapman CA, Rothman JM (2009). Within-species differences in primate social structure: evolution of plasticity and phylogenetic constraints. Primates 50: 12-22.

Chapman CA, Wrangham RW, Chapman LJ (1995). Ecological constraints on group size: an analysis of spider monkey and chimpanzee subgroups. Behavioral Ecology and Sociobiology 36: 59-70.
Clutton-Brock TH, Harvey PH (1977). Primate ecology and social organization. Journal of Zoology 183: 1-39.

Coudrat CNZ, Duckworth JW, Timmins RJ (2012). Distribution and conservation status of the red-shanked douc (Pygathrix nemaeus) in Lao PDR: an update. American Journal of Primatology 74: 874-889.

Cui L, Huo S, Zhong T, Xiang Z, Xiao W, Quan R (2008). Social organization of black-andwhite snub-nosed monkeys (Rhinopithecus bieti) at Deqin, China. American Journal of Primatology 70: 169-174.

Dominy NJ, Lucas PW, Osorio D, Yamashita N (2001). The sensory ecology of primate food perception. Evolutionary Anthropology 10: 171-186.

Dong T (2011). Ecology, Behavior and Conservation of the Tonkin Snub-Nosed Monkey (Rhinopithecus avunculus) in Vietnam. Thesis, Australian National University.

Duc HM, Baxter GS, Page MJ (2009). Diet of Pygathrix nigripes in Southern Vietnam. International Journal of Primatology 30: 15-28.

Ganzhorn JU (2003). Habitat description and phenology. In Field and Laboratory Methods in Primatology (Setchell JM, Curtis DJ, eds.), pp 40-56. Cambridge, Cambridge University Press.

Garber PA (1988). Diet, foraging patterns, and resource defense in a mixed species troop of $\mathrm{Sa}$ guinus mystax and Saguinus fuscicollis in Amazonian Peru. Behaviour 105: 18-34.

Gillespie TR, Chapman CA (2001). Determinants of group size in the red colobus monkey (Procolobus badius): an evaluation of the generality of the ecological-constraints model. Behavioral Ecology and Sociobiology 50: 329338.

Grueter CC, van Schaik CP (2009). Sexual size dimorphism in Asian colobines revisited. American Journal of Primatology 71: 609-616.

Grueter CC, van Schaik CPCP (2010). Evolutionary determinants of modular societies in colobines. Behavioral Ecology 21: 63-71.
Grueter CC, Chapais B, Zinner D (2012). Evolution of multilevel societies in nonhuman primates and humans. International Journal of Primatology 33: 1002-1037.

Grueter CC, Li D, Ren B, Wei F, Li M (2017a). Deciphering the social organization and structure of wild Yunnan snub-nosed monkeys (Rhinopithecus bieti). Folia Primatologica 88: 358-383.

Grueter CC, Qi X, Li B, Li M (2017b). Multilevel societies. Current Biology 27: R984-R986.

Grueter CC, Qi X, Zinner D, Bergman T, Migliano A, Li B, Li M, Xiang Z, Zhu P, Miller A, Krutzen M, Fischer J, Rubenstein D, Vidya T, Cantor M, Swedell L (2020). Multilevel organization of animal sociality. Trends in Ecology and Evolution 35: 834-847.

Guo S, Li B, Watanabe K (2007). Diet and activity budget of Rhinopithecus roxellana in the Qinling Mountains, China. Primates 48: 268-276.

Ha T (2009). Behavioural Ecology of Grey-shanked Douc Monkey in Vietnam. Cambridge, University of Cambridge.

Hoang M (2007). Ecology and Conservation Status of the Black-Shanked Douc (Pygathrix nigripes) in Nui Chua and Phuoc Binh National Parks, Ninh Thuan Province, Vietnam. PhD thesis, University of Queensland, Brisbane.

Kappeler PM (2019). A framework for studying social complexity. Behavioral Ecology and Sociobiology 73: 13 .

Kappeler PM, van Schaik CP (2002). Evolution of primate social systems. International Journal of Primatology 23: 317-332.

Kirkpatrick RC (1995). The natural history and conservation of the snub-nosed monkeys (genus Rhinopithecus). Biological Conservation 72: 363-369.

Kirkpatrick RC (2011). The Asian colobines: diversity among leaf-eating monkeys. In Primates in Perspective (Campbell CJ, Fuentes A, MacKinnon KC, Bearder SK, Stumpf RM, eds.), 2nd ed., pp 189-202. Oxford, Oxford University Press. 
Kirkpatrick RC, Gu H, Zhou X (1999). A preliminary report on Sichuan snub-nosed monkeys (Rhinopithecus roxellana) at Baihe Nature Reserve. Folia Primatologica 70: 117-120.

Kirkpatrick RC, Long YC, Zhong T, Xiao L (1998). Social organization and range use in the yunnan snub-nosed monkey Rhinopithecus bieti. International Journal of Primatology 19: 13-51.

Kummer H (1968). Social Organization of Hamadryas Baboons. Chicago, University of Chicago Press.

Lehmann J, Boesch C (2004). To fission or to fusion: effects of community size on wild chimpanzee (Pan troglodytes verus) social organisation. Behavioral Ecology and Sociobiology 56: $207-216$

Lippold LK (1977). The douc langur: a time for conservation. In Primate Conservation (Rainer H, Bourne GH, eds.), pp 513-538. New York, Academic Press.

Lippold LK (1995). Distribution and conservation status of douc langurs in Vietnam. Asian Primates 4: 4-6.

Lippold LK, Thanh VN (2008). The time is now: survival of the douc langurs of Son Tra, Vietnam. Primate Conservation 23: 75-79.

Long HT (2007). Distribution, population and conservation status of the grey-shanked douc (Pygathrix cinerea) in Gia Lai Province, central highlands of Vietnam. Vietnamese Journal of Primatology 1: 55-60.

Matsuda I, Kubo T, Tuuga A, Higashi S (2010). A bayesian analysis of the temporal change of local density of proboscis monkeys: implications for environmental effects on a multilevel society. American Journal of Physical Anthropology 142: 235-245.

Nadler T, Momberg F, Canh LX, Lermee N (2003). Vietnam Primate Conservation Status Review 2002: Part 2, Leaf Monkey. Frankfurt, Frankfurt Zoological Society and Fauna \& Flora International

Newton PN (1988). The variable social organization of hanuman langurs (Presbytis entellus), infanticide, and the monopolization of females. International Journal of Primatology 9: 59-77.

Ngoc Thanh V, Lippold L, Timmins RJ, Manh Ha $\mathrm{N}$ (2008). Pygathrix nemaeus. The IUCN Red List of Threatened Species.

Nhat P (1993a). Contributions to understanding primates and the morphological, biological, and ecological characteristics of rhesus macaques (Macaca mulatta), stump-tailed macaques (Macaca arctoides Geof.), douc langurs (Pygathrix nemaeus nemaeus Linn.), and tonkin snub-nosed monkeys (Rhinopithecus avunculus Dol.) in Vietnam. $\mathrm{PhD}$ thesis, National Science Center and Institute of Ecology and Biological Resources, Hanoi.

Nhat P (1993b). The distribution and status of the Douc langur Pygathrix nemaeus in Vietnam. Australian Primatology 8: 5-6.

O'Brien JA (2014). The Ecology and Conservation of Black-Shanked Doucs (Pygathrix nigripes) in Cat Tien National Park, Vietnam. Boulder, University of Colorado.
Patzelt A, Kopp GH, Ndao I, Kalbitzer U, Zinner D, Fischer J(2014). Male tolerance and malemale bonds in a multilevel primate society. Proceedings of the National Academy of Sciences of the United States of America 111: 14740-14745.

Patzelt A, Zinner D, Fickenscher G, Diedhiou S, Camara B, Stahl D, Fischer J (2011). Group composition of guinea baboons (Papio papio) at a water place suggests a fluid social organization. International Journal of Primatology 32: 652-668.

Phiapalath P (2009). Distribution, Behavior and Threat of Red-Shanked Douc Langur Pygathrix nemaeus in Hin Namno National Protected Area, Khammouane Province, Lao PDR. Thesis, Suranaree University of Technology.

Phiapalath P, Borries C, Suwanwaree P (2011). Seasonality of group size, feeding, and breeding in wild red-shanked douc langurs (Lao PDR). American Journal of Primatology 73: 1134-1144.

Qi X, Garber PA, Ji W, Huang Z, Huang K, Wang X, Guo S, He G, Zhang P, Li B (2014). Satellite telemetry and social modeling offer new insights into the origin of primate multilevel societies. Nature Communications 5: 5296.

Qi X-G, Li B-G, Garber PA, Ji W, Watanabe K (2009). Social dynamics of the golden snubnosed monkey (Rhinopithecus roxellana): female transfer and one-male unit succession. American Journal of Primatology 71: 670-679.

Ramos-Fernandez G, Boyer D, Gomez VP (2006). A complex social structure with fission-fusion properties can emerge from a simple foraging model. Behavioral Ecology and Sociobiology 60: 536-549.

Ratajszczak R, Cox R, Ha DD (1990). A Preliminary Survey of Primates in North Vietnam. Gland, World Wide Fund for Nature.

Rawson BM (2009). The socio-ecology of the blackshanked douc in Mondulkiri Province, Cambodia. Thesis, Australian National University.

Rawson BM, Roos C (2008). A new primate species record for Cambodia: Pygathrix nemaeus. Cambodian Journal of Natural History 1: 7-11.

Ren B, Li D, Garber PA, Li M (2012). Fission-fusion behavior in Yunnan snub-nosed monkeys (Rhinopithecus bieti) in Yunnan, China. International Journal of Primatology 33: 1096-1109.

Ruempler U (1998). Husbandry and breeding of douc langurs (Pygathrix nemaeus nemaeus) at Cologne Zoo. International Zoo Yearbook 36: 73-81.

Schaller GB (1985). China's golden treasure. International Wildlife 15: 29-31.

Sterling EJ, Hurley MM, Le DM (2006). Vietnam: A Natural History. New Haven, Yale University Press.

Tenaza RR (1989). Intergroup calls of male pigtailed langurs (Simias concolor). Primates 30 199-206.

Tenaza RR, Fuentes A (1995). Monandrous social organization of pigtailed langurs (Simias concolor) in the Pagai Islands, Indonesia. International Journal of Primatology 16: 295-310.
Thanh VN, Khoi LV, Quyet LK, Tri N, Van Vy TH, Bay LP (2007). Survey Results for RedShanked Douc Langur (Pygathrix nemaeus nemaeus) in Son Tra Nature Reserve, Da Nang City, Central Vietnam. Technical Report. Hanoi, Vietnam National University.

Tilson RL (1977). Social organization of simakobu monkeys (Nasalis concolor) in Siberut Island, Indonesia. Journal of Mammalogy 58: 202-212.

Timmins RJ, Duckworth JW (1999). Status and conservation of douc langurs (Pygathrix nemaeus) in Laos. International Journal of Primatology 20: 269-289.

Tordoff AW, Tran QB, Nguyen DT, Le MH (2004). Sourcebook of existing and proposed protected areas in Vietnam, 2nd ed. Hanoi, Birdlife International in Indochina and Ministry of Agriculture and Rural Development.

Ulibarri L (2013). The Socioecology of RedShanked Doucs (Pygathrix nemaeus) in Son Tra Nature Reserve, Vietnam. Boulder, University of Colorado.

Van Peenen PFD, Light RH, Duncan JF (1969). Observations on mammals of Mt. Sontra, South Vietnam. Mammalia 35: 126-143.

van Schaik CPP, van Noordwijk MA (1989). The special role of male Cebus monkeys in predation avoidance and its effect on group composition. Behavioral Ecology and Sociobiology 24: $265-276$.

van Schaik CP, Terborgh JW, Wright SJ (1993). The phenology of tropical forests: adaptive significance and consequences for primary consumers. Annual Review of Ecological Systems 24: 353-377.

Vogel ER, Dominy NJ (2011). Ecological methods. In Primates in Perspective (Campbell CJ, Fuentes A, MacKinnon KC, Bearder SK, Stumpf RM, eds.), 2nd ed., pp 123-138. Oxford, Oxford University Press.

Wallace RB (2008). Towing the party line: territoriality, risky boundaries and male group size in spider monkey fission-fusion societies. American Journal of Primatology 70: 271-281.

Williamson EA, Feistner ATC (2011). Habituating primates: processes, techniques, variables and ethics. In Field and Laboratory Methods in Primatology (Curtis DJ, Setchell JM, eds.), pp. 3350. Cambridge, Cambridge University Press.

Wrangham RW, Gittleman JL, Chapman CA (1993). Constraints on group size in primates and carnivores: population density and dayrange as assays of exploitation competition. Behavioral Ecology and Sociobiology 32: 199209.

Wunderground (2013). The Weather Channel. www.wunderground.com.

Xiang ZF, Yang BH, Yu Y, Yao H, Grueter CC, Garber PA, Li M (2014). Males collectively defend their one-male units against bachelor males in a multi-level primate society. American Journal of Primatology 76: 609-617.

Yeager CP (1991). Proboscis monkey (Nasalis larvatus) social organization: intergroup patterns of association. American Journal of Primatology 23: 73-86. 
Yeager CP (1992). Proboscis monkey (Nasalis larvatus) social organization: nature and possible functions of intergroup patterns of association. American Journal of Primatology 26: 133-137.

Yeager CP (1995). Does intraspecific variation in social systems explain reported differences in the social structure of the proboscis monkey (Nasalis larvatus)? Primates 36: 575-582.
Yeager CP (1998). Asian colobine social structure: ecological and evolutionary constraints. WWF-Indonesia Program Zoological Society of San Diego 39(April): 147-155.

Zhang P, Li BG, Qi XG, MacIntosh AJJJ, Watanabe $K$ (2012). A proximity-based social network of a group of Sichuan snub-nosed monkeys (Rhinopithecus roxellana). International Journal of Primatology 33: 1081-1095.
Zhang P, Watanabe K, Li B, Qi X (2008). Dominance relationships among one-male units in a provisioned free-ranging band of the Sichuan snub-nosed monkeys (Rhinopithecus roxellana) in the Qinling Mountains, China. American Journal of Primatology 70: 634-641.

Zhang P, Watanabe K, Li B, Tan CL (2006). Social organization of Sichuan snub-nosed monkeys (Rhinopithecus roxellana) in the Qinling Mountains, Central China. Primates 47: $374-$ 382 . 